stage. The image of the light source is now restored to the centre of the diaphragm, by adjusting the microscope axis so as to bring this normal to the platform. The light beam is finally centred by lateral adjustment of the platform.

The microscope illustrated is the Vickers Patholette, the hole in the centre of the base of which facilitates optical alignment. Using this or any other standard microscope fitted with a suitable dark ground substage condenser and binocular angled head, immunofluorescence of bacteria in clinical specimens as well as virusinfected cells in culture can be viewed in ordinary room lighting. As far as we are aware, no other equipment at present commercially available allows satisfactory viewing of immunofluorescence preparations of microorganisms in ordinary room lighting and with a binocular head on the microscope.

Fading of fluorescent images occurs with all forms of exciting radiation. The more intense this is the faster does fading occur. With the HBO100 or PEK110 lamp used in the equipment described, the rate of fading of the fluorescence is not so rapid as to constitute a serious inconvenience. Using a $50 \times$ fluorite objective lens with a $12 \times$ eye-piece, adequate photographic exposure of black and white film of ASA rating 125 has been obtained in about 30 seconds.

\section{Use of barium sulphate as a continuous marker for faeces}

\author{
MATTHEW DICK From the Metabolic Unit, \\ University College Hospital, London
}

The advantages of using continuous marking of faeces in metabolic balance studies is well established (Rose, 1964), the most common method being the chromium sesquioxide of Anderson and Weinbren (1961). This paper describes a new method using barium sulphate which requires no special apparatus or powerful and potentially dangerous oxidizing agents.

\section{REAGENTS}

ALKALINE E.D.T.A. $\mathrm{NaOH} 2.5 \%$, E.D.T.A. (disodium salt) $5 \%$ in water

METHYL RED Saturated solution in 50\% alcohol

AMMONIUM SULPHATE A $5 \%$ solution of $\left(\mathrm{NH}_{4}\right)_{2} \mathrm{SO}_{4}$ in $0.5 \mathrm{NHCl}$

\section{METHODS}

In our first trials, barium sulphate B.P. was administered in capsules, originally of $0.5 \mathrm{~g}$. four times daily with the main meals ( $12 \mathrm{~g}$. per six-day period). Later $8 \mathrm{~g}$. per sixday period, spread out as before, was used as this quantity was more suitable for the capsule packing machine in the hospital pharmacy, use of which avoided the labour of filling by hand. $\mathrm{BaSO}_{4}$ was given during the five-day equilibration period before the first carmine marker was taken, and continued until the last marker was passed. Collection of stools, homogenization, drying, and ashing were carried out in the normal manner, similar to that described by Rose (1964). The samples taken from the homogenate should be judged to contain about 100 to $300 \mathrm{mg}$. of $\mathrm{BaSO}_{4}$.

The ashed sample in a silica beaker is dissolved in $10 \mathrm{ml}$. of $30 \% \mathrm{HCl}$ with warming; to this $20 \mathrm{ml}$. of $\left(\mathrm{NH}_{4}\right)_{2} \mathrm{SO}_{4}$ solution is added and water to about $40 \mathrm{ml}$. The sample is mixed, allowed to stand for a few minutes, then the fluid (and fine $\mathrm{BaSO}_{4}$ ) decanted into a $50 \mathrm{ml}$. centrifuge tube which is centrifuged at 3,000 r.p.m. for five minutes. The supernatant is discarded and the $\mathrm{BaSO}_{4}$ returned to the original beaker by washing with water, $100 \mathrm{ml}$., alkaline E.D.T.A. added, and the beaker placed on a steam bath with occasional stirring until solution of the $\mathrm{BaSO}_{4}$ is complete (about one hour). Meanwhile, $50 \mathrm{ml}$. alkaline E.D.T.A. is added to the centrifuge tube in order to dissolve any very fine $\mathrm{BaSO}_{4}$ remaining.

The contents of the beaker are filtered through Whatman no. 54 paper into a conical flask, the E.D.T.A. solution in the centrifuge tube being then transferred to the beaker which is rewarmed on the steam bath for about 15 minutes, then filtered into the same flask and Received for publication 7 September 1966. 

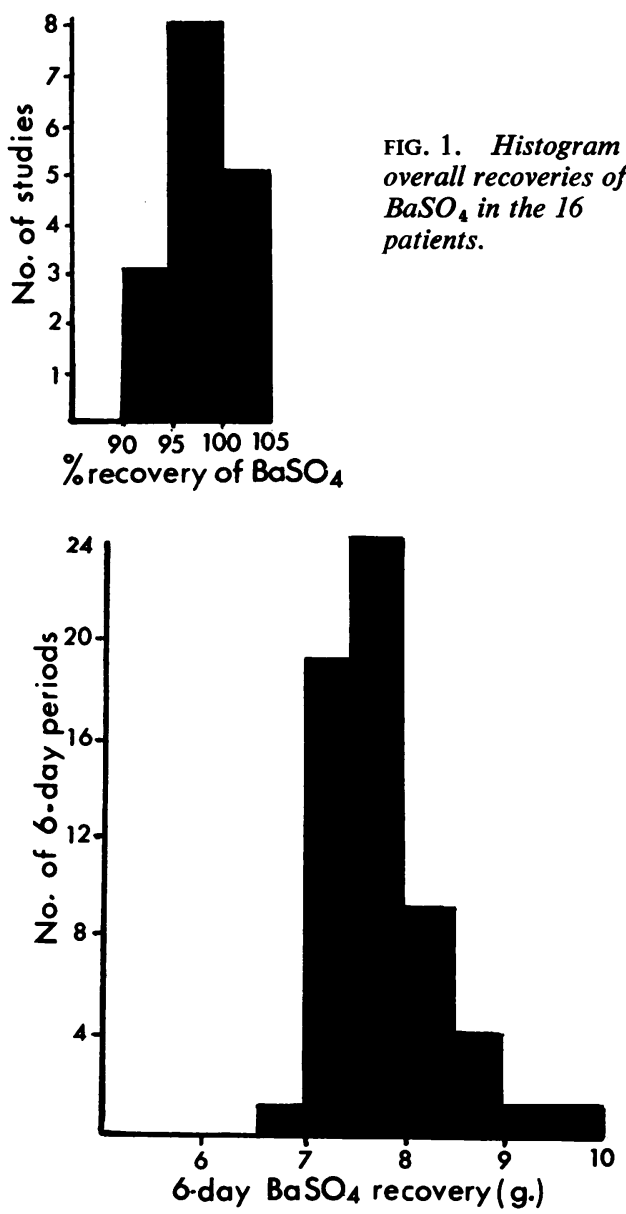

FIG. 2. Histogram of $\mathrm{BaSO}_{4}$ recoveries in the 59 balance periods.

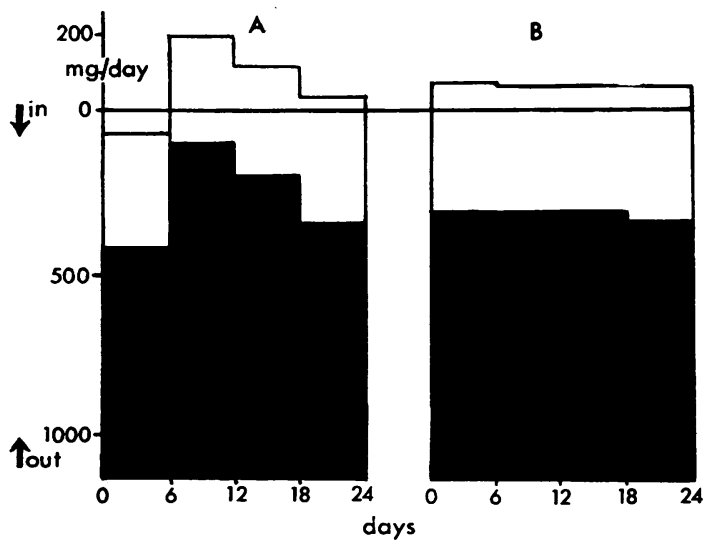

FIG. 3. Calcium balance (A) without and $(B)$ with $\mathrm{BaSO}_{4}$ correction. $\mathrm{BaSO}_{4}$ recoveries for the six-day periods were $6.5 \mathrm{~g} ., 9.3 \mathrm{~g} ., 8.5 \mathrm{~g}$, and $7.8 \mathrm{~g}$. Faecal excretion shaded. washed in with water. The filtrate is heated to boiling point, concentrated $\mathrm{HCl}$ added until just acid to methyl red, $10 \mathrm{ml}$. $\left(\mathrm{NH}_{4}\right)_{2} \mathrm{SO}_{4}$ solution added with shaking and the flask stood on a steam bath for about one hour. The precipitated $\mathrm{BaSO}_{4}$ is collected in a weighed sintered glass crucible (porosity 4) with gentle suction, washed with water, acetone, and ether, and dried at $120^{\circ} \mathrm{C}$. (about 30 minutes).

\section{RESULTS}

In two experiments when $\mathrm{BaSO}_{4}$ was added to stools already in the homogeniser, and six measured aliquots taken in each case for analysis, the recoveries were:

$197.2 \% ; 97.6 \% ; 98.4 \% ; 97.5 \% ; 97.9 \% ; 98.3 \%$

$297.8 \% ; 97.7 \% ; 97.3 \% ; 97.7 \% ; 97.3 \% ; 97.4 \%$.

The total $\mathrm{BaSO}_{4}$ recovery over 59 six-day balance periods on 16 patients was $97 \%$ of the $\mathrm{BaSO}_{4}$ administered. The minimum recovery in any patient was $90 \%$ and the maximum $104 \%$. The distribution of the total recoveries in each patient is shown in Fig. 1 and the individual $\mathrm{BaSO}_{4}$ analyses in Figure 2 . We have used Rose's (1964) format to facilitate direct comparison. An example of a calcium balance corrected and uncorrected for $\mathrm{BaSO}_{4}$ recovery is given in Figure 3. This was chosen because of a particularly difficult carmine marking problem in this subject. He was nevertheless a normal volunteer doctor well aquainted with our metabolic ward procedures.

\section{COMMENT}

This method, although possibly not quite as rapid as the chromium technique, has certain advantages. The necessary apparatus is both cheap and readily available, and the method avoids the use of potentially dangerous reagents such as perchloric acid. The barium sulphate in the dosage is well tolerated by patients, and any possibility of toxic effect has already been extensively investigated in its use as a contrast medium in radiology.

The method is very reproducible, showing an almost constant loss of $2 \%$ to $3 \%$, and the recoveries over a period of time compare favourably with those of Rose (1964). The overall recovery of $97 \%$ in 59 six-day periods confirms that the balance studies performed in this department before the use of a continuous marking technique did not suffer from serious error due to loss of stool. We have not encountered the surprisingly large variations of marker from period to period sometimes found by Rose (1964), but nevertheless, we agree with him that continuous marking is needed to improve the accuracy of the balance work. This is well illustrated in Fig. 3 which shows one of the largest variations in recovery of barium sulphate which we have seen. We now use barium sulphate in all balance work, usually in conjunction with carmine markers, but it is quite possible to dispense with carmine markers or to interrupt the balance at a stage between markers.

It would be theoretically possible to estimate calcium, phosphorus, and magnesium on the acid extract from the silica beaker, and thus perform the estimations on a single specimen, but we have preferred to use separate 
samples. If the latter technique is used and calcium is to be estimated spectrophotometrically on a separate acid extract, it would be advisable to add $\left(\mathrm{NH}_{4}\right)_{2} \mathrm{SO}_{4}$ to the acid extract before filtration (final concentration of $0.5 \%$ is suitable) in order to precipitate any $\mathrm{BaSO}_{4}$ solubilized by reduction during the ashing stage. With warm acid and the normal washings, calcium precipitation as sulphate does not present any problem.

Reduction during ashing is found especially where higher than normal concentrations of carbon and phosphorus are encountered. This was first noted in stools containing cellulose phosphate and we had poor recoveries of barium sulphate in these cases until it was counteracted by addition of ammonium sulphate.

Professor C. E. Dent suggested the use of barium sulphate and supervised the method. Thanks are due to Miss Christine Harper, Mrs. Helen Marshall, and Mrs. Mary Forbes who participated in the early stages of the method. The author is grateful to Dr. Lyal Watson for critical discussion and help in preparing this paper, and to Sister Norman and the nursing and dietetic staff of the Metabolic Unit.

\section{REFERENCES}

Anderson, J., and Weinbren, I. (1961). Clin. chim. Acta, 6, 648. Rose, G. A. (1964), Gut, 5, 274.

\section{Letters to the Editor}

\section{CERVICAL CYTOLOGY AND POPULATION SCREENING}

Sir,

'A cytohistopathologist's viewpoint' on related matters was the subject of a recent paper (McInroy, 1966) and the viewpoint was reiterated at the Annual General Meeting of the Association of Clinical Pathologists on 29 September 1966.

In October 1966, official guidance for planning population screening services was issued by the Ministry of Health (Memorandum $\mathrm{H} / \mathrm{Cl} / 01$ ) but this does not seem to me to provide all the answers.

This memorandum correctly states 'The basis for any screening service is the provision of cytological facilities for examining and reporting on cervical smears in hospital pathology laboratories'. In the very next sentence responsibility for this is transferred to hospital boards: 'Hospital boards are responsible for providing sufficient trained staff and accommodation.... In turn hospital management committees become involved because it is through them that requests for additional technical staff are normally made by hospital laboratories. It will be the experience of the majority of us that nobody at any level of administrative control seems to have the money to finance what we consider to be minimal additional technical and clerical staff requirements. Accordingly, although we agree with the Ministry's wisdom, 'The basis . . . is the provision of cytological facilities . . . in hospital laboratories', this is of little help if it cannot be financed and implemented.

My claim, which many may challenge, is that expansion of this service must be planned and administered on a subregional basis, each cytology unit being staffed by a consultant cytohistologist, a chief II technician (in technical charge), chief I technicians (three or more), and adequate clerical assistance. Where will the chief I technicians come from? The cytology technicians of the future will be recruited from the senior technicians of the present and the intake of additional laboratory staff will be at student level. This process must inevitably extend over a period of years. My reasons for this 'top-heavy' establishment have been given in the publication referred to above but until units of a type such as this come into existence I see little hope of a stable, efficient, full-scale, nation-wide service ever evolving.

In the Ministry's 'guiding' memorandum there is no reference to the staffing structure of cytology laboratories. It merely states 'normally only fully qualified medical laboratory technicians (or student or junior technicians) [my italics] specially trained in cytology should undertake the examination of cervical smears'. This to me suggests a complete lack of appreciation of the difficulties and problems which face pathologists.

The time is long overdue when pathologists, as a body, should make their voices heard and offer guidance for planning expansion and organization of this service. 